\title{
Fractal surfaces of synthetical DEM generated by GRASS GIS module r.surf.fractal from ETOPO1 raster grid
}

\author{
Polina Lemenkova ${ }^{1 *}$ \\ ${ }^{1}$ Ocean University of China, College of Marine Geo-sciences, Qingdao, Shandong, China.
}

\begin{abstract}
The research problem is about to generate artificial fractal landscape surfaces from the Digital Elevation Model (DEM) using a stochastic algorithm by Geographic Resources Analysis Support System Geographic Information System (GRASS GIS) software. Fractal surfaces resemble appearance of natural topographic terrain and its structure using random surface modelling. Study area covers KurilKamchatka region, Sea of Okhotsk, North Pacific Ocean. Techniques were included into GRASS GIS modules (r.relief, d.rast, r.slope.aspect, r.mapcalc) for raster calculation, processing and visualization. Module 'r.surf.fractal' was applied for generating synthetic fractal surface from ETOPO1 DEM GeoTIFF using algorithm of fractal analysis. Three tested dimensions of the fractal surfaces were automatically mapped and visualized. Algorithm of the automated fractal DEM modelling visualized variations in steepness and aspect of the artificially generated slopes in the mountains. Controllable topographic variation of the fractal surfaces was applied for three dimensions: dim=2.0001, 2.0050, 2.0100. Auxiliary modules were used for the visualization of DEMs (d.rast, r.colors, d.vect, r.contour, d.redraw, d.mon). Modules 'r.surf.gauss' and 'r.surf.random' were applied for artificial modelling as Gauss and random based mathematical surfaces, respectively. Univariate statistics for fractal surfaces were computed for comparative analysis of maps representing continuous fields by module 'r.univar': number of cells, min/max, range, mean, variance, standard deviation, variation coefficient and sum. The paper includes 9 maps and GRASS GIS codes used for visualization.
\end{abstract}

Keywords: GRASS GIS, Fractal surface, Digital elevation model, Grid, ETOPO1

\section{ETOPO1 raster verisinden sentetik SYM fraktal yüzeylerinin GRASS GIS r.surf.fractal modülü ile elde edilmesi}

Öz: Araștırma problemi, GRASS GIS yazılımı ile stokastik bir algoritma kullanılarak Sayısal Yükseklik Modeli'nden (SYM) yapay fraktal yüzeylerin üretilmesidir. Fraktal yüzeyler, doğal topografik arazinin görünümüne ve yapısina rastgele yüzey modellemesi kullanarak benzerler. Çalı̧̧ma alanı Kuril-Kamçatka bölgesini, Okhotsk Denizi'ni, Kuzey Pasifik Okyanusu'nu kapsamaktadır. Raster hesaplama, işleme ve görselleştirme için kullanılan yöntemler GRASS GIS modüllerini (r.relief, d.rast, r.slope.aspect, r.mapcalc) içermektedir. Fraktal analiz algoritması kullanılarak ETOPO1 DEM GeoTIFF'den sentetik fraktal yüzey oluşturmak için 'r.surf.fractal' modülü uygulanmıştır. Fraktal yüzeylerin test edilen üç boyutu otomatik olarak haritalanmış ve görselleştirilmiştir. Otomatik fraktal DEM modellemesinin algoritması kullanılarak dağlık alanlarda yapay olarak üretilen yamaçların dikliği ve yönü bakımından oluşturulan varyasyonlar ile görselleştirmeler yapılmıştır. Fraktal yüzeylerin kontrol edilebilir topografik varyasyonu üç boyut için uygulanmıştır: dim = 2.0001, 2.0050, 2.0100. DEM'lerin görüntülenmesi için yardımcı modüller kullanılmıştır (d.rast, r.colors, d.vect, r.contour, d.redraw, d.mon). Yapay modelleme için 'r.surf.gauss' ve 'r.surf.random' modülleri Gauss ve rasgele tabanll matematiksel yüzeyler olmak üzere sirasılyla uygulanmıştır. Fraktal yüzeyler için tek değişkenli istatistikler 'r.univar' modülüne göre sürekli alanları temsil eden haritaların karşılaştırmalı analizi için hesaplanmıştır: hücre sayısı, min / maks, aralık, ortalama, varyans, standart sapma, varyasyon katsayısı ve toplam. Makalede 9 harita ve görselleştirme için kullanılan GRASS GIS kodları bulunmaktadır.

Anahtar Sözcükler: GRASS GIS, Fraktal yüzey, Sayısal yükseklik modeli, Grid, ETOPO1 


\section{Introduction}

Fractals are infinitely complex patterns of the dynamic systems, self-similar across different scales created by repeating a recursive iterative process in a feedback loop (Briggs, 1992; Mandelbrot, 1982). The most well-known example of abstract fractals is Mandelbrot Set (Mandelbrot, 2004) represented by Benoit Mandelbrot, who first recognized fractal nature of Earth's relief. As commonly used and described both in pure mathematical and nature sciences (Edgar, 2007; Falconer, 2003; Feder, 2013; Gordon, 2000; Muzy, Bacry, \& Arneodo, 1993; Panchev, 1971); fractal algorithms are also well applicable in geographic studies for spatial analysis aimed at classifying and investigating variations in Earth's relief.

The phenomenon of Earth's topography consists in its partial self-similarity repeating fractal structure of the landscapes at various dimensions where the theory of fractals is well applicable. Simulating spatial fractals in topographic modelling uses the mathematics of fractal iterations and reproduces many of the spatial scaling patterns of the landscapes. Fractal dimension is the most important measure of the algorithm. Thus, as well known, the dimension of a line in Euclidean space is one, a plane area in the Cartesian XY coordinate system is two, and the 3 dimensional (3D) area is three. Depending on the curvature of the line, it may appear similar to a band and take a larger proportion of an area. Mandelbrot suggested computing the complexity (curvature) of a line by applying a single dimension between 1 and 2 for a line, or between 2 and 3 in a surface (Mandelbrot, 1967, 1975).

Development of the nonlinear theory of fractal surfaces in geospatial sciences mostly focused on the geological and environmental aspects, including the analysis of the landscape patchiness, ore minerals resources formation, growth and structure, soil taxonomy, geodynamics simulation, modelling resources distribution (Ibanez, Arnold, \& Ahrens, 2009; Imre, Novotný, \& Rocchini, 2012). The fractal modelling focuses on minimizing the divergence between mathematical models and natural reality of the Earth since the phenomena of the resource distribution is inherently irregular and it is not straightforward to quantify both its physical structure and geographic arrangement.

There are various methodological approaches to fractal modelling. For instance, several methods to estimate the fractal dimension of surface intensity were programmed in Matlab (Gonzales-Barron \& Butler, 2005), specially designed software used for plants' model generation as fractal objects was well-reviewed by De La Re, Abad, Camahort and Juan (2009) in An Ivy Generator (URL-1), FracTree (URL-2), botanic modelling by LStudio (URL-3), Xfrog modelling (URL-4). Fractal surfaces can be also generated by Python language (van Rossum \& Drake Jr, 1995) and by package 'fractal' in R programming language (R Core Team, 2017).

Practical applicability of the theory of fractals is quite diverse. Fractals are used to assess non-linear variability in geophysics (Malinverno, 1990; Schertzer \& Lovejoy, 1991, 1993), for universal graphical simulations (Pecknold, Lovejoy, Schertzer, Hooge, \& Malouin, 1993) or terrain generation and modelling (Pickover, 1995; van Pabst \& Jense, 1996), modelling artificial landscapes and other environmental data (Burrough, 1981), artificial modelling of the topographic surfaces, geomorphological and computer mapping (Mark \& Aronson, 1984; Scheidegger, 1970), texture analysis and classification (Peleg, Naor, Hartley, \& Avnir, 1983), in cartographic plotting (Dutton, 1981), in geomorphological terrain modelling and geomorphometry (Evans, 1972, 1979; Prusinkiewicz \& Hammel, 1993) to mention but a few.

Geographic Resources Analysis Support System Geographic Information System (GRASS GIS) is a scripting-based generalpurpose GIS for management, processing, analysis, modelling and visualization of georeferenced data. In GRASS GIS the idea of fractals algorithms is implemented by an 'r.surf.fractal' module, which enables to create artificial patterns on the surface from the initial raster grid using algorithms of surface generation (Saupe, 1988). The GRASS GIS module 
'r.surf.fractal' uses Fastest Fourier Transform in the West (FFTW) (URL-5), which is a comprehensive collection of fast routines of $\mathrm{C}$ programming language for computing the discrete Fourier transform (DFT) and its various special cases, well described in relevant technical documentation (Duhamel \& Vetterli, 1990; Frigo \& Johnson, 1997; Frigo \& Johnson, 1998; Frigo, 1999; Johnson \& Frigo, 2006). The FFTW transforms data both in one-dimensional and multi-dimensional input forms.

This study, focusing on the artificial topographic modelling of the Kuril region (Greater Kuril Chain and Sakhalin Island), aims to model topographic surface (curvature, slopes, shaded relief) based on Digital Elevation Model (DEM) and then to assess three fractal dimensions in order to establish the best-fitting model for the artificial spatial distribution of the geomorphic landforms using GRASS GIS algorithm. Natural landforms vary across the continuous Earth's surface varying in scales and sizes (Evans \& Cox, 2005) with flexible fractal patterns of the landscapes. The concept of the geographic scale and fractal dimensions introduced by Mandelbrot (1967) is based upon the assumption that topographic perception largely correlates with the generalization of the scale of the view. In other words, a combination of the size or dimensions of the area of interest (AOI) directly controls the extent of the observed terrain coverage. Second, the generalization of the topographic map presented in the minuteness and coverage of the classified DEM depends on the resolution of the input DEM, which is used as raw input data and on the fractal dimensions, as on the presented two scales of the fractals.

Therefore, the research questions of the study are as follows: 1) Can several topographic surface models in DEM be identified by GRASS GIS? 2) Which fractal dimensions from the proposed ones (dim=2.0001, dim=2.0050, dim=2.0100) can be identified as best-fitting models for the relief modelling for the difficult to access areas? 3) How a sequence of GRASS GIS modules (r.surf.fractal r.relief, d.shade, d.grid, d.frame, d.mon, d.rast, d.vect, r.colors, r.contour) can be u sed technically for plotting cartographic visualization through a shell scripting approach? 4) How can fractal maps be used as visual indexes to the topographic phenomena depicting relief objects that are contained in the Earth's landscapes through artificial geomorphological modelling? Through focusing on these questions, the current study is applying methods of artificial intelligence and machine learning as advanced methods contributing to the development of the traditional cartography through automatization techniques.

The research aim is to find an appropriate modelling scale for visualizing the behavior of topographic surfaces through testing of three various dimensions. Since topographic surfaces are statistically self-similar, and that a parameter of the fractal dimension is applicable at various scales, the paper aims to test if scale variations eventually affect final topographic models of the study area by fractals modelling. Thus, this paper aims at the empirical examinations of three dimensions (dim=2.0001, $\operatorname{dim}=2.0050, \operatorname{dim}=2.0100$ ) of the topographic samples covering the Kuril-Kamchatka region.

The objective of the study is represented by cartographic scripting in GRASS GIS in order to highlight technical possibilities of the GRASS GIS syntax for fractal modelling. The two objectives of this research are: 1) to identify the spatial distribution of various representative landforms artificially generated on the Kamchatka Peninsula; 2) to analyze cartographic functionality of the GRASS GIS with respect to its modelling techniques used for processing geoinformation. By building three fractal maps based on the ETOPO1 DEM, this study was expected to gain an impression of change in the dimension of scale, detail and shape of the relief landforms on the selected fragments of the study area.

\section{Methodology}

The methodology consists of the following steps: topographic mapping of the raster grids, automatic generating of the fractal surfaces of DEM; descriptive statistical analysis of the raster grids; masking raster surfaces from the initial datasets by 
'm.calc' module. The initial file (raster GeoTIFF in Cartesian coordinate system) was warped by the 'gdalwarp' utility of the Geospatial Data Abstraction Library (GDAL) into the georeferenced files (World Geodetic System 1984, WGS84). The Cylindrical Equal Area projection was used as a cartographic projection.

1. Plotting topographic map through GRASS GIS script by 'd.rast', 'd.vect', 'r.colors', 'r.contour' modules

2. Fractal analysis and generating artificial DEMs by modules 'r.surf.fractal', 'r.relief ', 'd.shade', 'd.grid'

3. Testing three dimensions through 'r.mapcalc' with increment=50 $(\mathrm{dim}=2.0001, \mathrm{dim}=2.0050, \operatorname{dim}=2.0100)$

4. Plotting two-facetted map using 'd.frame' and 'd.mon' modules

5. Statistical summary by modules 'r.report' and 'r.univar'

6. Gaussian surface generated by module 'r.surf.gauss' and random surface generated by 'r.surf.random' module

7. Masked topographic surface showing land areas and disabled water areas by queries of 'r.mapcalc' module

\subsection{Data and Study Area}

The study area is focused on the Kuril-Kamchatka Trench, Pacific Ocean (Figure 1, right). This region is geologically complex, notable for the lithosphere plate's subduction, high seismicity and active repetitive volcanism. Geomorphology is complicated through terraces, slopes and erosional processes. Modelling geomorphic features of such a region was performed through automated generating of the artificial terrain DEM surfaces and visualization of the datasets. The current research presents usage of several GRASS GIS modules proposing a solution for raster data processing and mapping: iterative modulebased scripting for automated generating of fractal surfaces and raster map calculator.

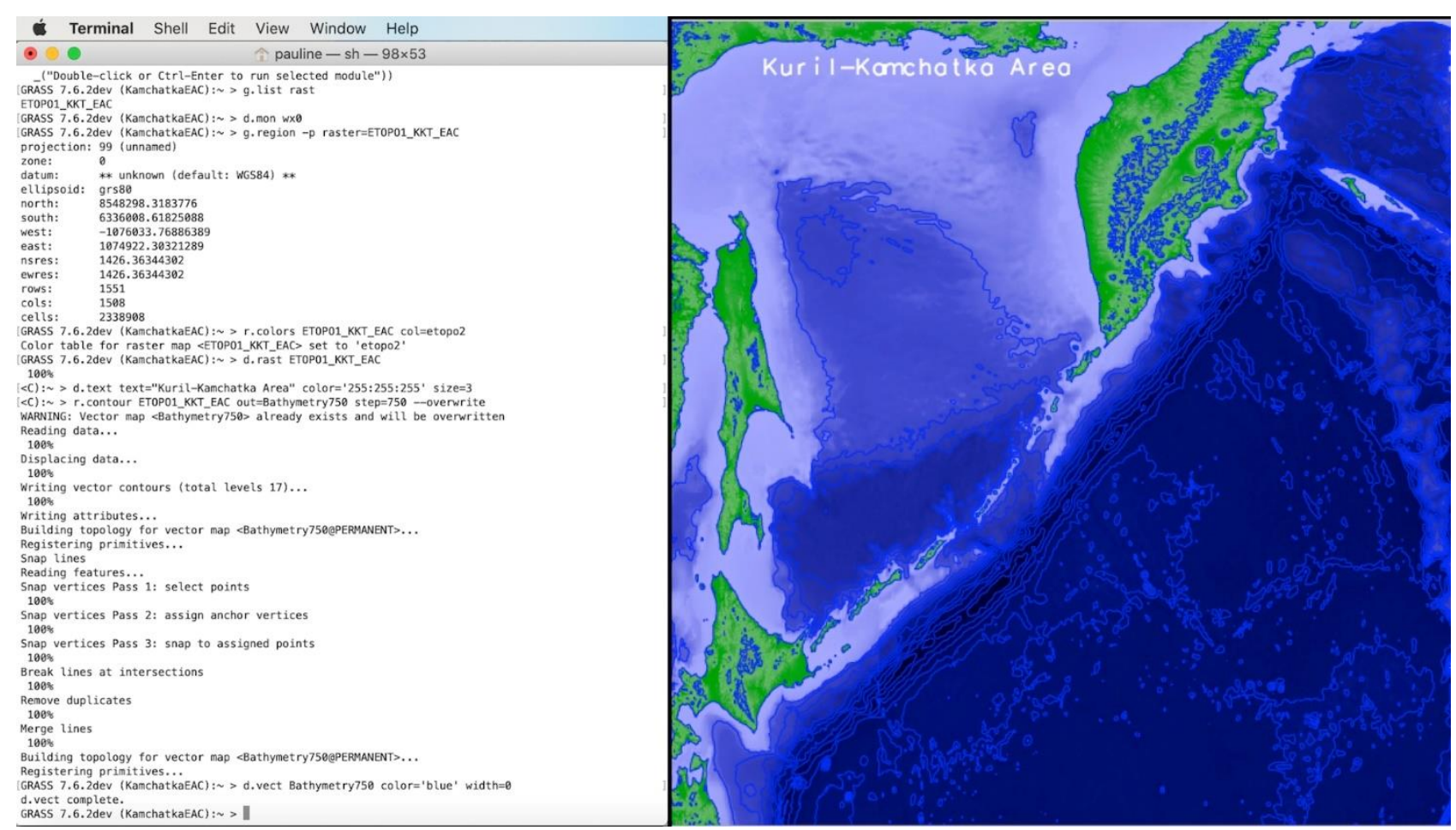

Figure 1: Plotting topographic map through GRASS GIS scripting (left) and resulting graphical output (right)

In this study, the ETOPO1 dataset was selected as the most appropriate one for the selected scale level of studied objects 
(Kamchatka Peninsula and Kuril-Kamchatka Trench) due to the following reasons. Geomorphic features, such as trenches, troughs, ridges, mountains, can be classified at middle scale while small furrows, local slopes and seamounts can only be seen at larger scales. On the contrary, if the goal is to map and portray prominent objects at a global coverage (e.g. tectonic plates boundaries and continents), then zooming to a smaller scale and adjusting grid resolution to coarser one (e.g. ETOPO5) can enable focus on the largest and most macro-scale features of the Earth. The DEM grid data were imported as raster files to the GRASS GIS environment and digitized contours of elevation covering study area of Kamchatka region (Sea of Okhotsk).

\subsection{Scripting Algorithms}

The main features of the GRASS GIS methodology consist of its scripting approach, which distinguishes it from other traditional GIS with Graphical User Interface (GUI). Therefore, the technical methodology of GRASS GIS is explained in more detail, in several logical steps, as follows.

\subsubsection{Topographic Visualization}

Dataset includes ETOPO1 1 Arc-Minute Global Relief Model used as an input raster grid in GeoTIFF format (Amante \& Eakins, 2009). The initial GeoTIFF grid was converted to WGS84 datum and reprojected by GDAL 'gdalwarp' utility into to Cylindrical Equal Area projection using following code:

- gdalwarp -t_srs '+proj=cea lat_ts=50 lon_0=155' ETOPO1_KKT_WGS84.tif ETOPO1_KKT_EAC.tif

The GRASS module 'r.relief ' was used to create a shaded relief map based on DEM. The 'd.rast' module was used to visualize input grid (ETOPO1_KKT_EAC). The color palette was selected using 'r.colors' using the code:

- $\quad$ 'r.colors' ETOPO1_KKT_EAC col=etopo2. This is a rainbow color ramp initially designed for the ETOPO2 2 minute Worldwide Bathymetry/Topography dataset but also applicable for the ETOPO1 grid.

Cartographic elements were added using the following code snippets:

- $\quad$ 'd.rast' ETOPO1_KKT_EAC used to display raster;

- $\quad$ 'd.text' text="Kuril-Kamchatka Area" color='255:255:255' size=3, used to add title on the map.

The contour isolines were added using the following codes:

- $\quad$ 'r.contour' ETOPO1_KKT_EAC out=Bathymetry750 step=750 -overwrite, which plots contours to a map by producing a vector map of the topographic contours from the initial raster map doing steps through incremental contours (here, every $750 \mathrm{~m}$ ).

- 'd.vect' Bathymetry750 color='blue' width=0, that is visualizing isolines.

\subsubsection{Fractal Analysis through r.surf.fractal Module}

The fractal dimensions of a surface were applied to the study area. Several two dimensions of fractal analysis were tested and obtained in new layers by module 'd.mon' (d.mon wx0, wx1, wx2, respectively). Following three fractal dimension values were tested: $\operatorname{dim}=2.0001, \operatorname{dim}=2.0050, \operatorname{dim}=2.0100$. Fractal dimensions were measured using GRASS 'r.surf.fractal' module techniques. Iteration of the algorithm is derived from the texture analysis algorithm of images using the spectral synthesis method. Created shaded relief map from an elevation map (here: KKRfractals, that is Kuril-Kamchatka Region fractals) is 
shown in Figure 2 (left). Script showing usage of 'd.shade', 'r.info' and 'r.contour' for generating shaded map, check up statistical data and visualizing isolines is shown on Figure 2 (right). Scripting application has been performed in four following steps:

- $\quad$ r.surf.fractal output=KKRfractals

- $\quad$ r.colors map=KKRfractals color=byr

- $\quad$ r.relief input=KKRfractals output=fractals_shade

- d.mon wx1 (starting a display monitor)

- d.shade shade=fractals_shade color=fractals $b=50$ (displaying shaded relief map, $b=$ integer showing $\%$ to brighten, here selected as 50; shade=fractals_shade shows a map to display)

The r.surf.random was applied to produce a raster image of uniform random deviates with the following expressed range:

- g.region $-p \mathrm{n}=505200 \mathrm{~s}=515000 \mathrm{w}=1550000 \mathrm{e}=1565000$ res=100 (here, the coordinates are set up and resolution was set to 100)

- r.surf.random out=KKRrandom $\min =0 \max =1000-$ overwrite (here the extreme range was set up to $0-1000$ )
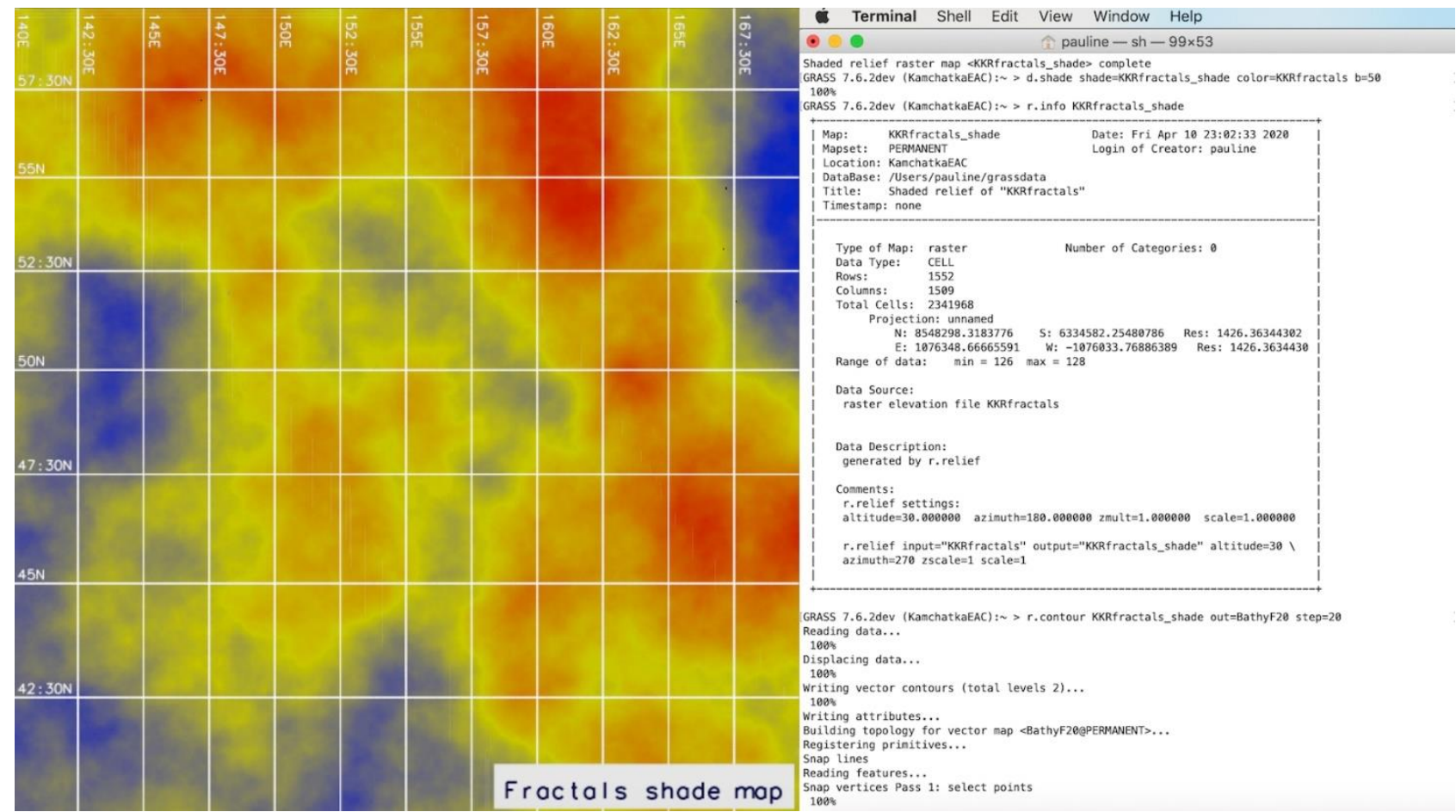

Figure 2: Shade map derived from the artificially generated fractals (left) and the script (right), GRASS GIS

\subsubsection{Testing Dimensions through r.mapcalc Module}

Since fractal analysis tests the complexity of the surface using the fractal dimension, two dimensions have been tested in this approach by 'r.mapcalc' module used as raster map calculator. Because the fractal dimension of 3.00 should be set between 2 and 3, three variants were tested: 
- $\quad$ 'r.surf.fractal' out=KKRdem_d2_0001 dim=2.0001

- $\quad$ 'r.surf.fractal' out=KKRdem_d2_0050 dim=2.0050

- $\quad$ 'r.surf.fractal' out=KKRdem_d2_0100 dim=2.0100

Workflow process of the DEM generation of the fractal surface by 'r.surf.fractal' dim=2.0050, contour by 'r.contour' with increment step $=20$ and aspect map with dimension $=2.0050$ is shown on the print-screen of the GRASS GIS console menu (example for dimension $\operatorname{dim}=2.0050$, repeated iteratively for $\operatorname{dim}=2.0001$ and $\operatorname{dim}=2.0100$ ) and script in Xcode, dimension $\operatorname{dim}=2.0001$ (Figure 3).

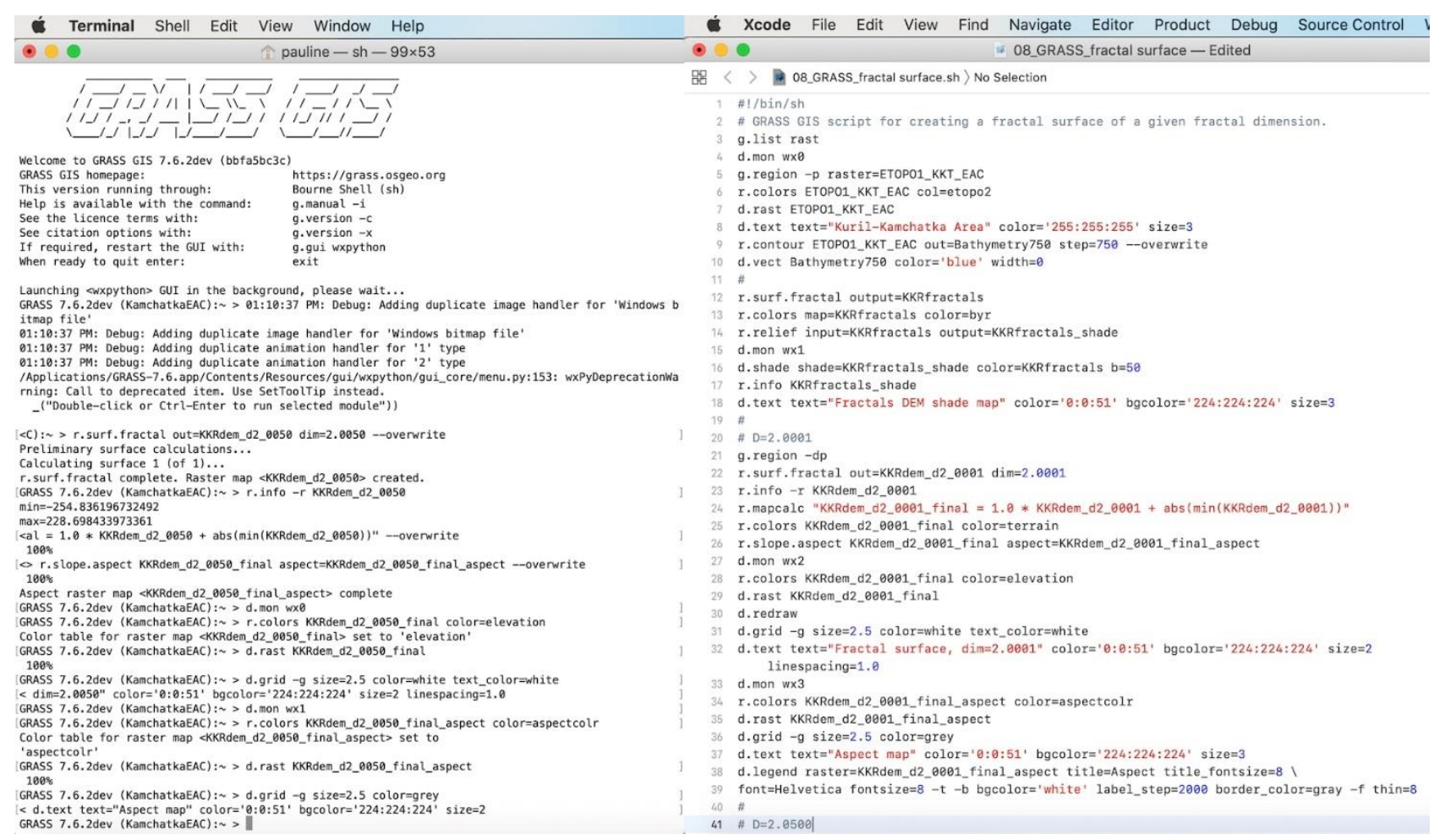

Figure 3: Fragment of the GRASS GIS console menu (left) and shell script used for plotting fractal surfaces (right)

The output fractal surfaces (Figures 4, 5 and 6) simulate natural terrain DEM with its structure depending on the fractal dimension. The facetted plot of the two maps was visualized using 'd.frame' module of GRASS GIS using following code:

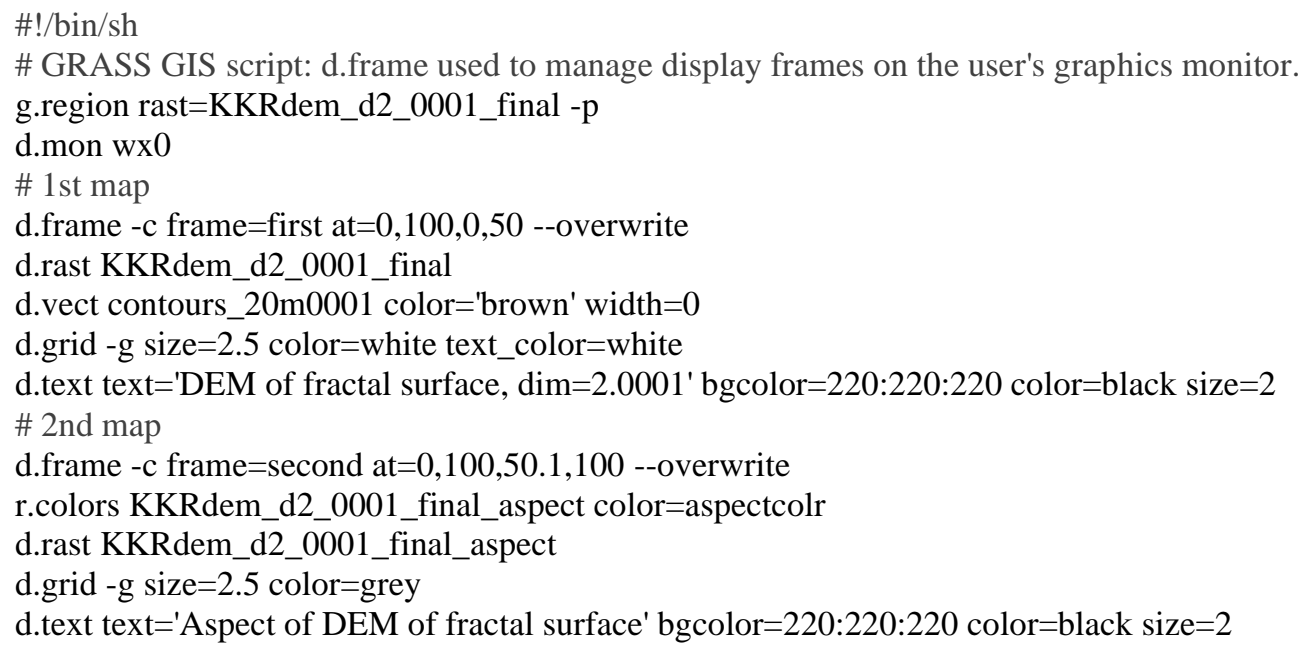

Likewise, other maps (Figures 5 and 6) were plotted using 'd.frame' module that splits monitor to various parts and enables 
to place several facetted maps on one layout.

At the next step, the 'r.mapcalc' module was used to create a mask for elevation showing only topographic areas of land and disabling those of water areas. This was done using the following code snippet:

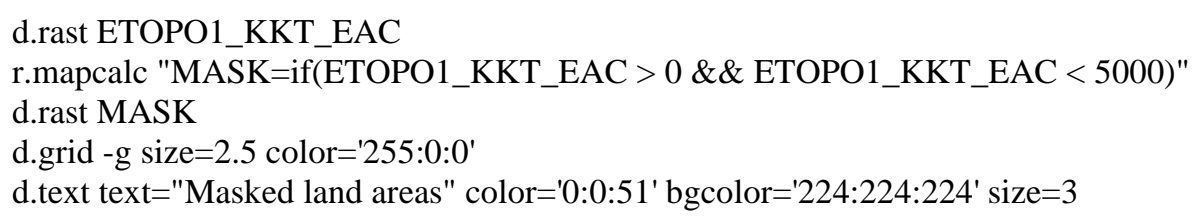

\subsubsection{Statistical Analysis}

The statistical analysis is important step in geospatial data processing and mostly based on the existing approaches and methods of statistical computing, as demonstrated in multiple previous research, for example, regression analysis (Breiman \& Friedman, 1985; Friedman, 1991; Lemenkova, 2019g, 2019i), various approaches of the statistical modelling (Cressie, 1993; Duchesnay \& Löfstedt, 2019; Lemenkova, 2019b, 2019d; Santner, Williams, \& Notz, 2003).

Standard deviation in the statistical analysis was computed by formula (1)

$s=\sqrt{\frac{1}{N-1} \sum_{i=1}^{N}\left(x_{i}-x\right)^{2}}$

where $x_{i}$ runs to $x_{N}$, as the observed elevation values of the DEM heights, and $x$ is the mean value of these samples, and $N$ is the number of observations in the sample DEM. The math of the computation algorithm is embedded in GRASS GIS.

The variation coefficient is computed by formula (2)

$S=S / x \times 100$

\section{Results and Analysis}

The generated fractal elevation cells depicting heights and depths were better correlated to the fractal dimension dim=2.0001 followed by the fractal dimensions $\operatorname{dim}=2.0050$ and $\operatorname{dim}=2.0100$, respectively. The range of the finest dimension corresponded to a topographic surface of the Kurils area, the best as depicting the Kamchatka peninsula and Greater Kuril Chain. The degree of cells uniformity showed good correlation to the mass fractal dimension of the middle size $($ dim=2.0050) followed by the coarser dimension $\operatorname{dim}=2.0100$ as lesser modelling regional topography. Specifically, based on the 'r.info' module of GRASS GIS (r.info -r KKRdem_d2_0100), the DEM with dimension dim=2.0100 has the following extension: $\min =-200.719623808808, \max =297.260467786757$, while DEM with dimension 2.0050 has the following extension: $\min =-$ 298.892860487009, $\max =202.902561370033$, and DEM with dimension 2.0001 has the following extension: min=232.525331632277, $\max =267.051157065383$. The last one (that is, DEM with dimension 2.0001) depicts the real world topography the best. Therefore, the fine resolution provides better results in fractal modelling.

The output fractal surfaces (Figures 4, 5, and 6) simulate natural terrain DEM with its structure depending on the fractal dimension (Mandelbrot, 1982). Difference between Figures 4, 5 and 6 shows various fractal dimensions (dim=2.0001 in Figure 4; $\operatorname{dim}=2.0050$ in Figure 5; $\operatorname{dim}=2.0100$ in Figure 6), which lie between the Euclidian dimensions of two (plane) and three (3D). Hence, the curvature and ruggedness of the topography in generated relief are depending on the fractal dimension, which increases it when the dimension is closer to 3 (compare Figure 6 to Figure 4 and Figure 5 as the middle variant). The 
results suggest that fractal dimension reflects the frequency of variation in the elevation data (heights and depths) as well as the aspect and the amplitude of the relief. Graphical simulations representing different topographic models for the three dimensions are seen on the resulting maps (Figures 4-6). Those figures are plotted by 'd.rast' GRASS GIS module. They show the synthetically generated distribution of the topographic model of the study area.

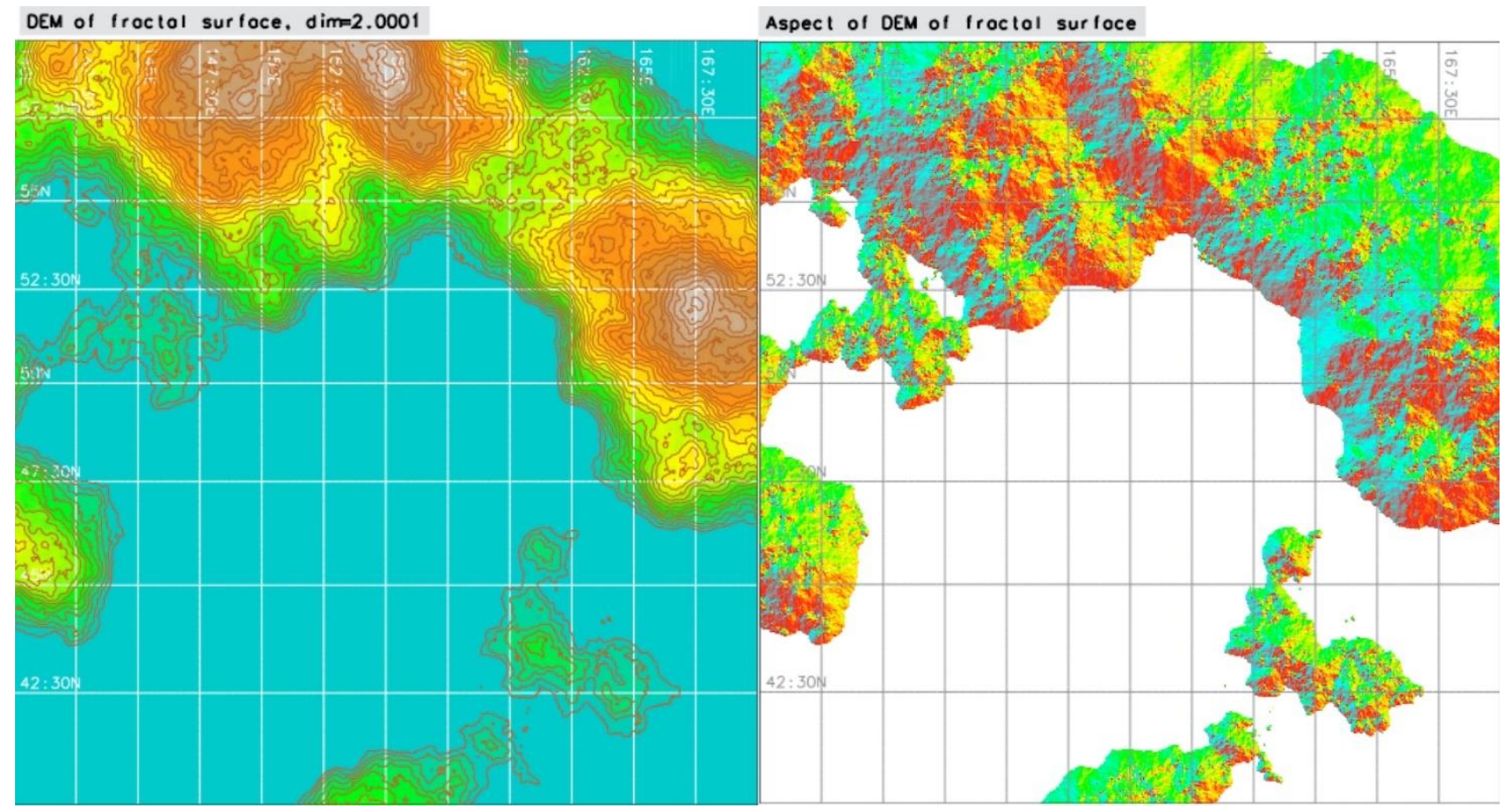

Figure 4: Elevation DEM of fractal surface generated by 'r.surf.fractal' dim=2.0001, contour by 'r.contour' with increment step=20 (left); aspect map with dimension $=2.0001$

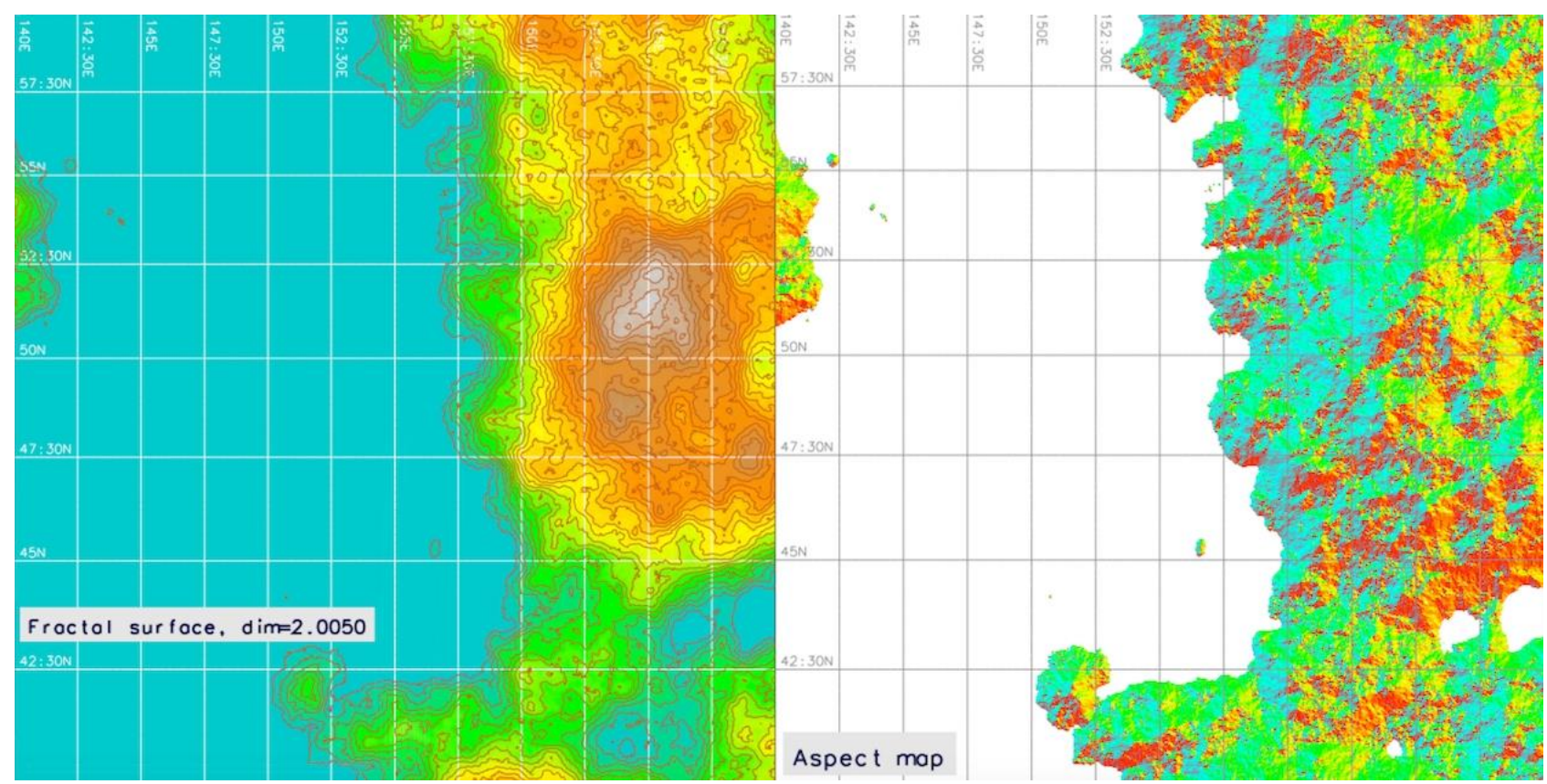

Figure 5: Elevation DEM of fractal surface generated by 'r.surf.fractal' dim=2.0050, contour by 'r.contour' with increment step=20 (left); aspect map with dimension $=2.0050$

Raster map statistics have been achieved by GRASS module 'r.univar', which computed univariate statistics for three raster maps of the artificial fractal surfaces (Figures 4, 5, and 6). Since all the three maps represent continuous fields, univariate 
statistics are applicable to perform comparative analysis. As can be seen, the standard deviation $=132.342$ has the highest values by fractal dimension=2.0001 (see, Figure 4). Standard deviation $=108.156$ by fractal dimension map with middle dimension=2.0050 (see, Figure 5) and finally, it values 106.360 by fractal dimension map with middle dimension=2.0100 in Figure 6. Hence, it decreases with the increase of fractal dimension, which means that elevation values (heights) on the map with higher fractal dimension are closer to their statistical mean, or the expected value. On the contrary, map with lower fractal dimension (Figure 4) has elevation values that spread out over a wider range and are less regular statistically. Variation coefficient is a relative standard deviation, which is a standardized measure of dispersion of a probability distribution or frequency distribution (Everitt, 1998). The script (Figure 7, left) computes the number of cells, minimum, maximum, range, arithmetic mean, variance, standard deviation, variation coefficient and the sum of all values. The parameters were tested by various modules of GRASS GIS for querying and summarizing maps of the land surfaces. Module 'r.report' was used to create a frequency distribution of the map values in the form of a table containing category numbers, labels and area sizes in kilometers (Figure 7, right). For the measured fractal surfaced the variation coefficient is 154.124 (or 1.54 in decimal values) for the fractal dimension=2.0001; 145.746 (1.45 in decimal values) for the dimension=2.0050 and 181.58 (1.81 in decimal values) for the dimension=2.0100. The Gaussian surface (Figure 8, left) shows random values around the mean value of 100 with standard deviation 10. The output map (Figure 8, right) is following the principle of the 'r.surf.gauss' in generating random surface. However, in representation view it uses a linear random number generator, in contrast to the Gaussian surface (Figure 8). The distribution of the elevation values in form of a bar chart (Figure 8, left) and Gauss bell-shaped curve (Figure 8 , right) is done using GRASS GIS module 'd.histogram' used to demonstrate and visualize statistical data.

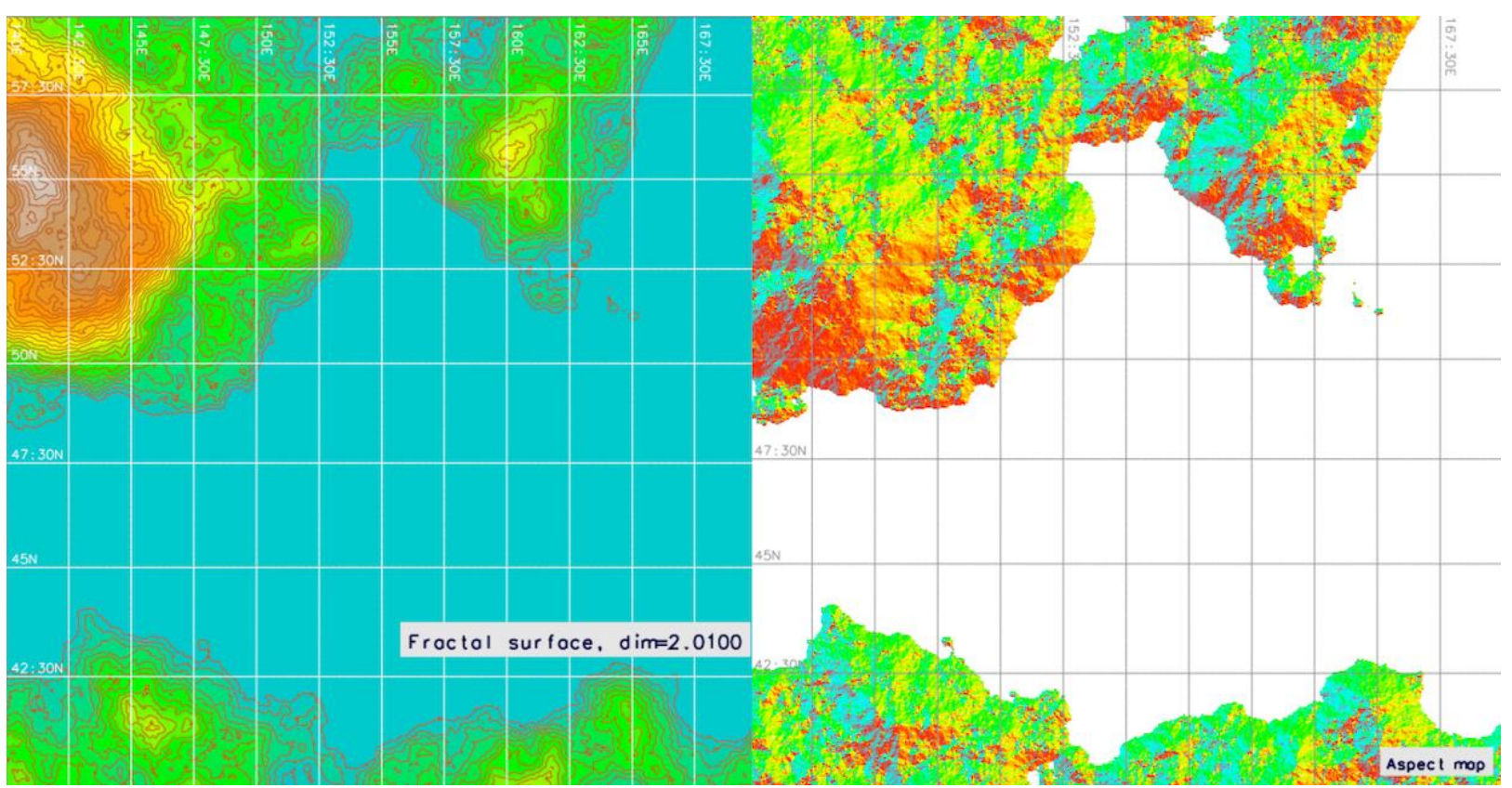

Figure 6: Elevation DEM of fractal surface generated by 'r.surf.fractal' dim=2.0100, increment step=20 (left) and aspect map with dimension $=2.0100$

Comparing the results of the statistical analysis, the following remarks were given based on data processing through the 'r.univar' module and summarized on Figure 7. The topographic surface based on three sample scenarios mapped with a total number of cells in a raster grid is 2338 908. Fractal dimension=2.0050 showed the following statistical results: maximum= 457.397, mean of absolute values $=74.2074$, standard deviation $=108.156$. The topographic surface based on fractal dimension=2.0100 showed the following statistical results: maximum $=594.521$, mean of absolute values=58.5745, standard deviation=106.36. The topographic surface based on fractal dimension=2.001 showed the following statistical results: maximum $=534.102$, mean of absolute values $=85.8675$, standard deviation $=132.342$. 
Based on the statistical histogram modelling, the minimal cell value is 17, the maximal is 41 (Figure 8). Gauss distribution (Figure 8, right) shows standard bell-shaped data distribution with a peak at 36.000. Fractal analysis of topographic surface patterns has been visualized to be a source of more precise information about DEM-induced variations in elevations. Fractal analysis is able to show dynamics of the elevation distribution in space taking into account the frequency of the surface heights in a real DEM, while direct mapping analysis of the topography shows the only static existing distribution of the terrain. Flat geomorphological surfaces (shelf areas) have lower values by finer fractal dimension. These regions indicate low surface roughness and curvature of the slopes. On the contrary, areas of complicated topography have low fractal dimensions (Grater Kuril Chain). The output of the 'r.mapcalc' module used to create a mask for elevation showing only topographic areas of land and disabling those of water areas is shown on Figure 9.

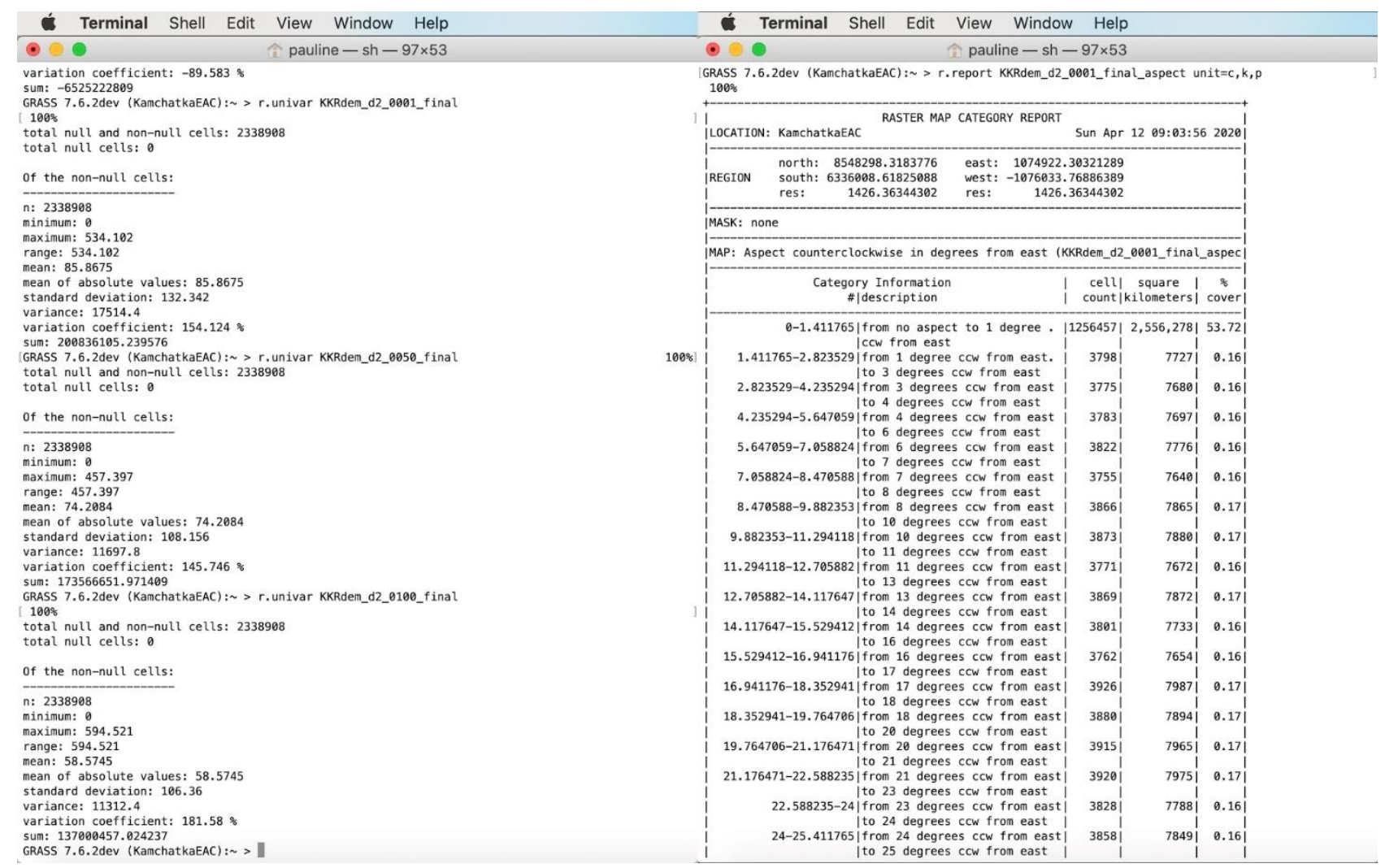

Figure 7: Fragment of GRASS GIS console showing executing univariate statistics by module 'r.univar' (left) and report on the summaries for aspect raster map: area sizes for each category (NWES) with parameter units: number of cells, area in $\mathrm{km}^{2}, \%$ cover(right)

\section{Conclusions and Suggestions}

The main goal of this paper was to demonstrate a useful functionality of a relatively new concept of fractal topographic modelling and surface differentiation with a dimensional order in GIS. Hence, the results were made using 'r.surf.fractal' module of GRASS GIS to generate multi-dimensional surfaces from the initial DEM based on the ETOPO1. The paper started by the description of a theoretical background regarding fractal theory and its practical applications in natural sciences and in geoinformatics, followed by the developed methodology using various software approaches (e.g. R, Python, Matlab, GRASS GIS). Modelling topographic surfaces in GRASS GIS was then stepwise explained in "Methodology" section and three resulting surfaces were presented in the "Results and Analysis" section, supported by statistical calculations. Thus, the paper presents an illustration of the fractal modelling application with a case study of the Far East region of the Pacific Ocean. Based on the global ETOPO1 gridded data processed by GRASS GIS, this study presented fractal measure to interpret topographic elevations by using quantitative (fractal dimension) approach of the fractal geometry through module 
'r.surf.fractal'. Hence, this paper investigated the fractal properties of the landforms in the Kuril-Kamchatka region and the surrounding area.
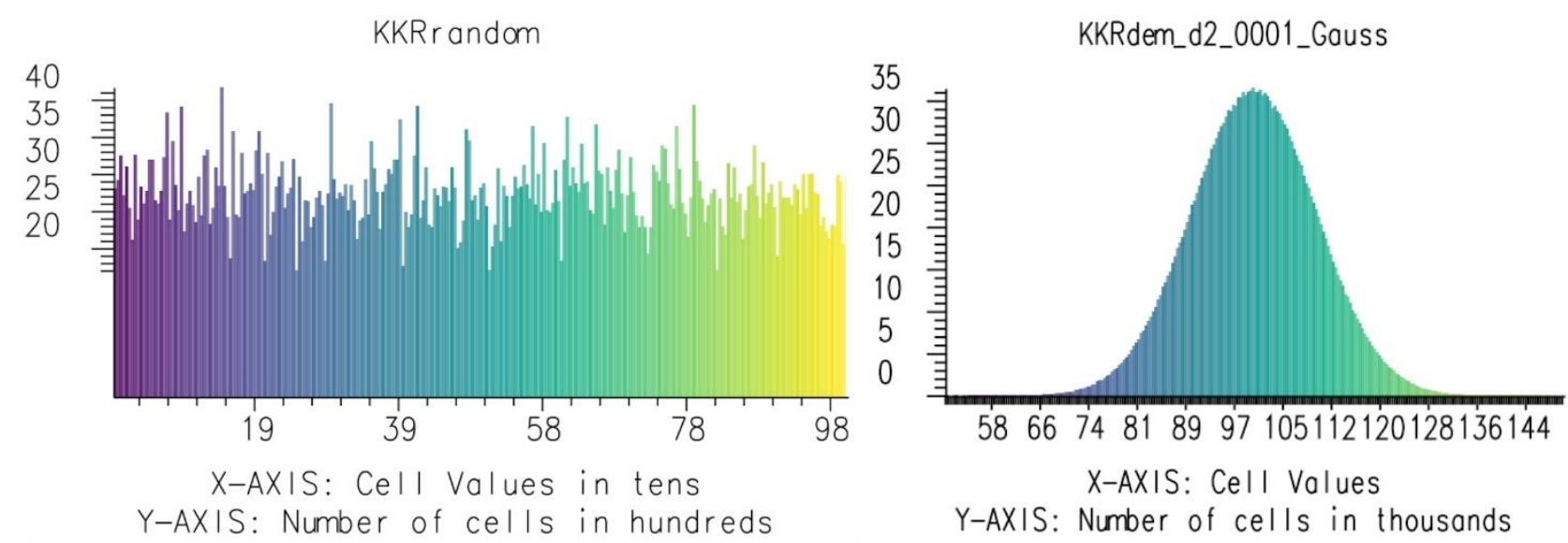

Figure 8: Random surface generated by 'r.surf.random' module of GRASS GIS (left). Gaussian surface generated by GRASS GIS module 'r.surf.gauss' (right). Applied 'viridis' color table for both rasters

Demonstrated functionality of GRASS GIS software is illustrated by processing raster input grid ETOPO1 and using various modules of raster data mapping. Methodology of several GRASS modules was shown and explained followed by computed various types of raster maps (Figures $1-9$ ). Generated fractal surfaces in three tested selected dimensions across the study area of the Kamchatka region were automatically mapped using machine learning algorithm. Developed algorithm of the semi-automated fractal DEM modelling enabled to visualize variations of the possible slope steepness of the mountainous areas of the region. The data were modelled to show gradient variations using shaded relief (GRASS module 'd.shade'). The results of the comparative fractal surface analysis revealed statistical variations for three dimensions: dim=2.0001, $\operatorname{dim}=2.0050, \mathrm{dim}=2.0100$. Presented research provided quantitative insights into the application of mathematical algorithms of DEM surface modelling to geoinformatics. Besides existing approaches in the computed-assisted cartographic modelling (e.g. Lemenkova, 2019c, 2019e, 2020a), tested modelling demonstrated the effectiveness of the GRASS GIS: a variety of GRASS GIS modules, mathematical algorithms and cartographic design tools that can be used to produce high-quality maps. The GRASS GIS listings are provided for repeatability.

Among other advantages of the GRASS GIS, its native scripting language has a direct correlation with its GUI menu that increases its functionality for the GIS users. For example, using another scripting cartographic toolset, such as Generic Mapping Tools (GMT), require fully operating technics of console-based scripting for mapping from the command line (e.g. Lemenkova, 2019f, 2019h, 2019k, 20191; Weatherall et al., 2015) while traditional GIS, such as ArcGIS (e.g. Klaučo, Gregorová, Stankov, Marković, \& Lemenkova, 2013, 2015; Suetova, Ushakova, \& Lemenkova, 2005) miss the functionality and open source availability of the GRASS GIS. Automatization in spatial data analysis is presented in various literature and methods are constantly developing (Gauger et al., 2007; Lemenkova, 2019a, 2020b, 2020c; Schenke \& Lemenkova, 2008). GRASS GIS has a powerful methodological platform with cartographic functionality: over 350 modules, GUI as well as command line based interface. Therefore, using GRASS GIS significantly enlarges existing methods of automated data processing by selecting necessary modules. As demonstrated in this paper by generating surface fractals, GRASS enables gridding irregularly spaced point data of the raster cells for machine-generated surface plotting in several steps by sequential use of the GRASS GIS modules.

The concept of fractals is a challenging approach in many fields, e.g. geomorphometry, geophy sics, geology, environment, geography, soil taxonomy. The current paper demonstrated a random machine-based fractal surface generated by 
'r.surf.fractal' module of GRASS GIS. According to Mandelbrot (1982), the majority of the existing land surfaces have a fractal dimension in the range of 2.2-2.6. More generally, most of the surfaces have a dimension in the range between 2.0 and 3.0. Nevertheless, landscapes usually exceed single fractal dimension. Instead, they can be best represented by a variety of the tested dimensions that vary with scale. Hence, the concepts of the topographic fractal surfaces and dimensions were used in this paper to generate synthetic, natural-looking surfaces covering Kuril-Kamchatka area. Controllable topographic variation of the fractal surfaces was applied.

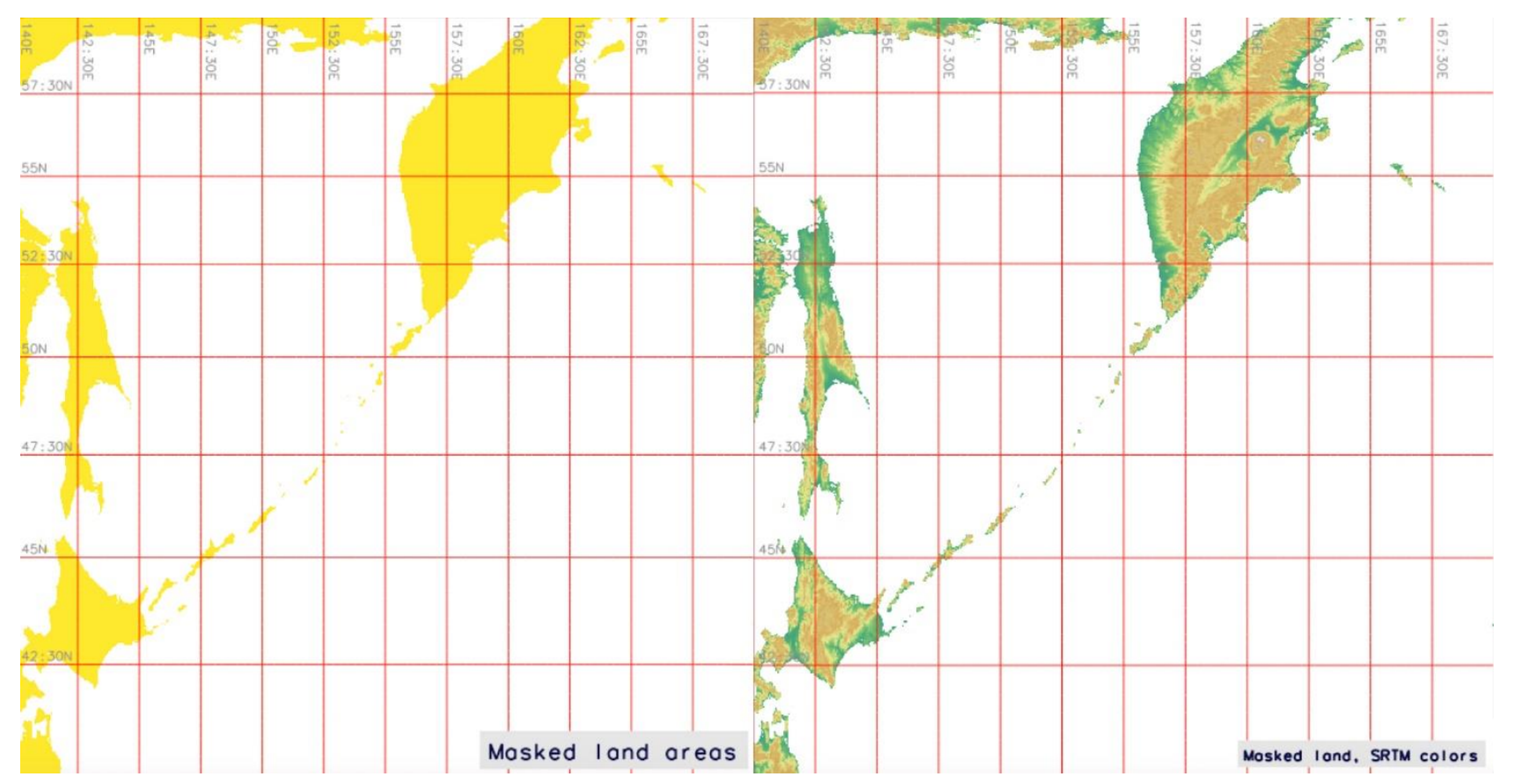

Figure 9: Masked topographic surface showing land areas and disabled water areas by queries of 'r.mapcalc' module of GRASS GIS (left). Applied SRTM color table (right), Greater Kuril Chain and Kamchatka Peninsula

The selection of GRASS GIS software is explained by its advantages over other GIS software. Examples include AWK and Octave (Lemenkova, 2019j), R programming language (Lemenkova, 2018a, 2018b), Google Earth imagery (Lemenkova, 2015a), ILWIS GIS (Lemenkova, 2015b), Caris HIPS and ArcGIS (Kuhn et al., 2006; Lemenkova, Promper, \& Glade, 2012; Lemenkova, 2015c). GRASS GIS is a mature, fully-featured open-source GIS that was used for spatial calculations in geomorphometry, as demonstrated in this paper with a focus on fractal-based artificial surface generation. The ANSI C source code of GRASS GIS provides a comprehensive suite of modules and UNIX-shell scripts to manipulate with DEMs, extract a variety of the land-surface parameters and geomorphological objects, as well as analyze geomorphological phenomena. Considerable automation has been built into the GRASS GIS, which features both GUI and a console-based command line interface.

This study demonstrated the technical application of the GRASS GIS 'r.surf.fractal' module which applies a spectral synthesis approach for generating fractal surfaces from DEM. Other fractal-related modules were used as auxiliary tools for technical visualization of the generated DEMs (e.g. 'd.rast', 'r.colors', 'd.vect', 'r.contour', 'd.redraw', 'd.mon'). Additionally, GRASS modules 'r.surf.gauss' and 'r.surf.random' were applied to perform artificial modelling of the mathematical surfaces (Gauss and random based). Of these, a module 'r.surf.gauss' was used to generate a fractal surface based on Gaussian random number generator whose mean and standard deviation were compared and described for three dimensions $(\operatorname{dim}=2.0001, \mathrm{dim}=2.0050$, $\operatorname{dim}=2.0100$ ). GRASS module 'r.surf.random' was applied for machine-generated raster image visualization that uses different types of random number generators. Both modules were tested in this paper. The presented paper contributes to the technical 
development of the cartographic methods by demonstrating GRASS GIS applicability for geomorphometric analysis.

As a suggestion for future studies, fractal modelling can be applied to the analysis of the parts of the landscapes, selected AOI, smaller polygons. Variations in the fractal dimensions can be achieved by slicing DEM. It is also recommended to use extracted 2D isolines from the general topographic map to calculate fractal dimension of the surface in order to perform local spatial analysis. Furthermore, it is recommended to use fractal analysis for statistical morphometric computations in geomorphometry to analyze the curvature of the bathymetric submarine relief, which is useful in geomorphological studies where the direct observations are missing, study objects are unreachable or topographic survey is too cost-expensive. Fractal analysis can furthermore be applied for the tectonic and geological studies to autodetect faults and geomorphological features (Gloaguen, Marpu, \& Niemeyer, 2007). Finally, big data can be processed using GRASS GIS functionality in order to test larger areas of coverage. For example, using GRASS GIS modules can enable efficient handling of dense elevation in topographic datasets and quantification of the land-surface variations.

To conclude, advances in mapping technologies, especially rapid evolution of the data processing, robotics and the machine learning approaches bring significant changes to the geomorphic analysis and cartographic techniques. High mapping efficiency makes repeated and automated mapping at short-time intervals real phenomena of the technological development, resulting in artificially generated DEMs. Concept of the machine learning in cartography requires new approaches in geomorphometry, which is focused on the computer-based data processing rather than human-operated routine. As a response, the GRASS GIS modules accommodate big data sets rapidly produced by new mapping technologies and new tools. Therefore, the proposed research is a contribution to the cartographic development applied for the selected study area of Kamchatka, North Pacific Ocean.

\section{Acknowledgements}

The research was funded by China Scholarship Council (CSC), State Oceanic Administration (SOA), Marine Scholarship of China, Grant Nr. 2016SOA002, China.

\section{References}

Amante, C., \& Eakins, B. W. (2009). ETOPO1 1 Arc-Minute Global Relief Model: Procedures, Data Sources and Analysis. NOAA Technical Memorandum NESDIS NGDC-24. National Geophysical Data Center, NOAA.

Breiman, L., \& Friedman, J. H. (1985). Estimating optimal transformations for multiple regression and correlation. Journal of the American Statistical Association, 80(391), 580-598.

Briggs, J. (1992). Fractals: The Patterns of Chaos: A new aesthetic of art, science, and nature. New York, Simon and Schuster. pp. 192. Burrough, P. (1981). Fractal dimensions of landscapes and other environmental data. Nature, 294(5838), 240-242.

Cressie, N. (1993). Statistics for Spatial Data, revised edition, Wiley Series in Probability and Statistics. In Applied Probability and Statistics. Wiley \& Sons New York.

De La Re, A., Abad, F., Camahort, E., \& Juan, M. C. (2009). Tools for procedural generation of plants in virtual scenes. In International Conference on Computational Science. pp. 801-810. Springer, Berlin, Heidelberg.

Duchesnay E., \& Löfstedt T. (2019). Statistics and Machine Learning in Python. Release 0.2. http://www.python.org, Accessed: 12 April 2020.

Duhamel, P. \& Vetterli, M. (1990). Fast Fourier transforms: a tutorial review and a state of the art. Signal Processing, 19, $259-299$.

Dutton, G. H. (1981). Fractal enhancement of cartographic line detail. The American Cartographer, 8(1), 23-40.

Edgar, G. (2007). Measure, topology, and fractal geometry. Springer Science \& Business Media. 
Evans, I. S. (1972). General geomorphometry, derivatives of altitude, and descriptive statistics. Spatial analysis in geomorphology, 17-90.

Evans, I. S. (1979). An integrated system of terrain analysis and slope mapping: Final Report on U.S. Army Grant DA-ERO-591-73-g0040. Statistical characterization of altitude matrices by computer. Department of Geography, University of Durham, England, pp. 192.

Evans, I. S., \& Cox, N. J. (2005). Global variations of local asymmetry in glacier altitude: separation of north-south and east-west components. Journal of glaciology, 51(174), 469-482.

Everitt, B. (1998). The Cambridge Dictionary of Statistics. Cambridge, UK: Cambridge University Press.

Falconer, K., (2003). Fractal Geometry: Mathematical Foundations and Applications (2 ${ }^{\text {nd }}$ ed.). John Wiley \& Sons, pp. 332.

Feder, J. (2013). Fractals. Springer Science \& Business Media. pp. 11.

Friedman, J. H. (1991). Multivariate adaptive regression splines. The Annals of Statistics, 19(1), 1-67.

Frigo, M., \& Johnson, S. G. (1997). The fastest Fourier transform in the west. Technical Report MIT-LCS-TR- 728, Massachusetts Institute of Technology Cambridge.

Frigo, M., \& Johnson, S. G. (1998). FFTW: An adaptive software architecture for the FFT. Proceedings of the IEEE International Conference on Acoustics, Speech, and Signal Processing, 3, pp. 1381-1384.

Frigo, M. (1999). A Fast Fourier Transform Compiler. Proceedings of the 1999 ACM SIGPLAN Conference on Programming Language Design and Implementation pp. 169-180.

Gauger, S., Kuhn, G., Gohl, K., Feigl, T., Lemenkova, P., \& Hillenbrand, C.-D. (2007). Swath-bathymetric mapping. Reports on Polar and Marine Research, 557, pp. 38- 45.

Gloaguen, R., Marpu, P. R., \& Niemeyer, I. (2007). Automatic extraction of faults and fractal analysis from remote sensing data. Nonlinear Processes in Geophysics, 14, pp. 131-138.

Gonzales-Barron, U., \& Butler, F. (2005). A comparison of visual assessment and digital fractal texture analysis of bread-crumb features. In Using Cereal Science and Technology for the Benefit of Consumers. pp. 395-400. Woodhead Publishing.

Gordon, N. (2000). Introducing fractal geometry. pp. 71.

Ibanez, J. J., Arnold, R. W., \& Ahrens, R. J. (2009). The fractal mind of pedologists (soil taxonomists and soil surveyors). Ecological complexity, 6(3), 286-293.

Imre, A. R., Novotný, J., \& Rocchini, D. (2012). The Korcak-exponent: a non-fractal descriptor for landscape patchiness. Ecological complexity, 12, 70-74.

Johnson, S. G., \& Frigo, M. (2006). A modified split-radix FFT with fewer arithmetic operations. IEEE Transactions on Signal Processing, 55(1), 111-119.

Klaučo, M., Gregorová, B., Stankov, U., Marković, V., \& Lemenkova, P. (2013). Determination of ecological significance based on geostatistical assessment: a case study from the Slovak Natura 2000 protected area. Open Geosciences, 5(1), 28-42.

Klaučo, M., Gregorová, B., Stankov, U., Marković, V., \& Lemenkova, P. (2015). Land planning as a support for sustainable development based on tourism: A case study of Slovak Rural Region. Environmental Engineering and Management Journal, 2(16), 449-458.

Kuhn, G., Hass, C., Kober, M., Petitat, M., Feigl, T., Hillenbrand, C. D., Kruger, S., Forwick, M., Gauger, S., \& Lemenkova, P. (2006). The response of quaternary climatic cycles in the South-East Pacific: development of the opal belt and dynamics behavior of the West Antarctic ice sheet. Bremerhaven, Germany, 94.

Lemenkova, P., Promper, C., \& Glade, T. (2012). Economic assessment of landslide risk for the Waidhofen ad Ybbs region, Alpine Foreland, Lower Austria.

Lemenkova, P. (2015a). Google Earth web service as a support for GIS mapping in geospatial research at universities. In Web-Technologies in the Educational Space. Problems, Approaches, Perspectives. pp. 24.

Lemenkova, P. (2015b). Innovations in the Geoscience Research: Classification of the Landsat TM Image Using ILWIS GIS for Geographic Studies. Prospects for the Higher School Development, pp. 60-63.

Lemenkova, P. (2015c). Data Capture for Seafloor Bathymetric Mapping Using Software Caris Hips, GMT and ArcGIS. Actual Problems of the Modern Machinery, pp. 111-117.

Lemenkova, P. (2018a). Factor Analysis by R Programming to Assess Variability Among Environmental Determinants of the Mariana Trench. Turkish Journal of Maritime and Marine Sciences, 4(2), 146-155.

Lemenkova, P. (2018b). R Scripting Libraries for Comparative Analysis of the Correlation Methods to Identify Factors Affecting Mariana Trench Formation. Journal of Marine Technology and Environment, 2, 35-42. 
Lemenkova, P. (2019a). Processing Oceanographic Data by Python Libraries Numpy, Scipy and Pandas. Aquatic Research, 2 (2), 73-91.

Lemenkova, P. (2019b). Statistical Analysis of the Mariana Trench Geomorphology Using R Programming Language. Geodesy and Cartography, 45(2), 57-84.

Lemenkova, P. (2019c). An empirical study of R applications for data analysis in marine geology. Marine Science and Technology Bulletin, 8(1), 1-9.

Lemenkova, P. (2019d). Numerical Data Modelling and Classification in Marine Geology by the SPSS Statistics. International Journal of Engineering Technologies, 5(2), 90-99.

Lemenkova, P. (2019e). Geospatial Analysis by Python and R: Geomorphology of the Philippine Trench, Pacific Ocean. Electronic Letters on Science and Engineering, 15(3), 81-94.

Lemenkova, P. (2019f). Topographic surface modelling using raster grid datasets by GMT: example of the Kuril-Kamchatka Trench, Pacific Ocean. Reports on Geodesy and Geoinformatics, 108(1), 9-22.

Lemenkova, P. (2019g). Testing Linear Regressions by StatsModel Library of Python for Oceanological Data Interpretation. Aquatic Sciences and Engineering, 34, 51-60.

Lemenkova, P. (2019h). Geomorphological modelling and mapping of the Peru-Chile Trench by GMT. Polish Cartographical Review, 51(4), 181-194.

Lemenkova, P. (2019i). Regression Models by Gretl and R Statistical Packages for Data Analysis in Marine Geology. International Journal of Environmental Trends, 3(1), 39-59.

Lemenkova, P. (2019j). AWK and GNU Octave Programming Languages Integrated with Generic Mapping Tools for Geomorphological Analysis. GeoScience Engineering, 65(4), 1-22.

Lemenkova, P. (2019k). GMT Based Comparative Analysis and Geomorphological Mapping of the Kermadec and Tonga Trenches, Southwest Pacific Ocean. Geographia Technica, 14(2), 39-48.

Lemenkova, P. (20191). Automatic Data Processing for Visualising Yap and Palau Trenches by Generic Mapping Tools. Cartographic Letters, 27(2), 72-89.

Lemenkova, P. (2020a). Visualization of the geophysical settings in the Philippine Sea margins by means of GMT and ISC data. Central European Journal of Geography and Sustainable Development, 2(1), 5-15.

Lemenkova, P. (2020b). GMT-based geological mapping and assessment of the bathymetric variations of the Kuril-Kamchatka Trench, Pacific Ocean. Natural and Engineering Sciences, 5(1), 1-17.

Lemenkova, P. (2020c). GMT Based Comparative Geomorphological Analysis of the Vityaz and Vanuatu Trenches, Fiji Basin. Geodetski list, 74(1), 19-39.

Malinverno, A. (1990). A simple method to estimate the fractal dimension of a self-affine series. Geophysical Research Letters, 17(11), 1953-1956.

Mandelbrot, B. (1967). How long is the coast of Britain? Statistical self-similarity and fractional dimension. Science, 156, 636-638.

Mandelbrot, B. (1975). Stochastic models for the Earth's relief, the shape and the fractal dimension of the coastlines, and the number-area rule for islands. Proceedings of the National Academy of Sciences, 72(10), 3825-3828.

Mandelbrot, B. (1982). The Fractal Geometry of Nature. San Francisco, W. H. Freeman \& Co. pp. 460.

Mandelbrot, B. (2004). Fractal aspects of the iteration of $\mathrm{z} \rightarrow \lambda \mathrm{z}(1-\mathrm{z})$ for complex $\lambda$ and $\mathrm{z}$. In Fractals and Chaos. pp. 37-51. Springer, New York, NY.

Mark, D. M., \& Aronson, P. B. (1984). Scale-dependent fractal dimensions of topographic surfaces: an empirical investigation, with applications in geomorphology and computer mapping. Journal of the International Association for Mathematical Geology, 16(7), 671-683.

Muzy, J. F., Bacry, E., \& Arneodo, A. (1993). Multifractal formalism for fractal signals: The structure-function approach versus the wavelet-transform modulus-maxima method. Physical review E, 47(2), 875.

Panchev, S. (1971). Random Functions and Turbulence. Pergamon, Oxford.

Pecknold, S., Lovejoy, S., Schertzer, D., Hooge, C., \& Malouin, J. F. (1993). The simulation of universal multifractals, Cellular Automata.

Peleg, S., Naor, J., Hartley, R., \& Avnir, D. (1983). Multiple-resolution texture analysis and classification. Computer Science Department, University of Maryland, College Park.

Pickover, C. A. (1995). Generating extraterrestrial terrain. IEEE Computer Graphics and Applications, 15(2), 18-21. 
Prusinkiewicz, P., \& Hammel, M. (1993). A fractal model of mountains and rivers. In Graphics Interface. 93, pp. 174-180. Canadian Information Processing Society.

R Core Team (2017). R: A language and environment for statistical computing. R Foundation for Statistical Computing, Vienna, Austria. https://www.R-project.org/

Santner, T. J., Williams, B. J., \& Notz, W. I. (2003). The design and analysis of computer experiments. New York: Springer.

Saupe, D. (1988). Algorithms for random fractals. In The science of fractal images. pp. 71-136. Springer, New York, NY.

Scheidegger, A. (1970). Theoretical Geomorphology. Springer Verlag.

Schenke, H. W., \& Lemenkova, P. (2008). Zur Frage der Meeresboden-Kartographie: Die Nutzung von AutoTrace Digitizer für die Vektorisierung der Bathymetrischen Daten in der Petschora-See. Hydrographische Nachrichten, 25(81), 16-21.

Schertzer, D., \& Lovejoy, S. (1991). Non-linear Variability in Geophysics: Scaling and Fractals. Kluwer Academic Publishers.

Schertzer, D., \& Lovejoy, S. (1993). Nonlinear Variability in Geophysics 3: Scaling and Multifractal Processes, Institut D'études Scientifiques de Cargèse. Institut d'études scientifiques de Cargèse.

Suetova, I., Ushakova, L., \& Lemenkova, P. (2005). Geoinformation mapping of the Barents and Pechora Seas. Geography and Natural Resources, 4, 138-142.

van Pabst, J. V. L., \& Jense, H. (1996). Dynamic terrain generation based on multifractal techniques. In High Performance Computing for Computer Graphics and Visualisation. pp. 186-203. Springer, London.

van Rossum, G., \& Drake Jr, F. L. (1995). Python reference manual. Amsterdam: Centrum voor Wiskunde en Informatica, Amsterdam. Weatherall, P., Marks, K. M., Jakobsson, M., Schmitt, T., Tani, S., Arndt, J. E., Rovere, M., Chayes, D., Ferrini, V. \& Wigley, R. (2015). A new digital bathymetric model of the world's oceans. Earth and Space Science, 2(8), 331-345.

URL-1: An Ivy Generator, http://graphics.uni-konstanz.de/ luft/ivy_generator (Accessed: 11 May 2020)

URL-2: FracTree, http://archives.math.utk.edu/software/msdos/fractals/fractree (Accessed: 11 May 2020)

URL-3: LStudio, http://algorithmicbotany.org (Accessed: 11 May 2020)

URL-4: Xfrog, http://www.xfrog.com/ (Accessed: 11 May 2020)

URL-5: FFTW, http://www.fftw.org/ (Accessed: 12 April 2020) 